\title{
The effects of temperature, body mass and feeding on metabolic rate in the tsetse fly Glossina morsitans centralis
}

\author{
J O H N S T ER B L A N C H E and S T E V E N L. C H O W N \\ Centre for Invasion Biology, Stellenbosch University, Stellenbosch, South Africa.
}

\begin{abstract}
Metabolic rate variation with temperature, body mass, gender and feeding status is documented for Glossina morsitans centralis. Metabolic rate [mean \pm $\mathrm{SE} ; \mathrm{VCO}_{2}=19.78 \pm 3.11 \mu \mathrm{L} \mathrm{CO}_{2} \mathrm{~h}^{-1}$ in males (mean mass $=22.72 \pm 1.41 \mathrm{mg}$ ) and $27.34 \pm 3.86 \mu \mathrm{L} \mathrm{CO}_{2} \mathrm{~h}^{-1}$ in females (mean mass $=29.28 \pm 1.96 \mathrm{mg}$ ) at $24{ }^{\circ} \mathrm{C}$ in fasted individuals] is strongly influenced by temperature, body mass and feeding status, but not by gender once the effects of body mass have been accounted for. A significant interaction between gender and feeding status is seen, similar to patterns of metabolic rate variation documented in Glossina morsitans morsitans. Synthesis of metabolic rate-temperature relationships in G. m. centralis, G. m. morsitans and Glossina pallidipes indicate that biting frequency as well as mortality risks associated with foraging will probably increase with temperature as a consequence of increasing metabolic demands, although there is little evidence for variation among species at present. Furthermore, metabolic rate-body mass relationships appear to be similarly invariant among these species. These data provide important physiological information for bottom-up modelling of tsetse fly population dynamics.
\end{abstract}

Key words. Insect vector, Q10 effect, respiration rate, sex-related variation, temperature effects.

\section{Introduction}

Metabolic rate reflects the cost of living for an organism under a specific set of environmental conditions. In consequence, considerable attention has been given to metabolic rate and the factors influencing its variation (Chown \& Nicolson, 2004). In insects, metabolic rate responds rapidly to changes in activity and ambient temperature, and scales positively with body mass. However, it is also influenced by other factors, such as time of day, gender, feeding status, pregnancy, maturation (age), diapause, season, latitude and elevation (Chown \& Nicolson, 2004; Terblanche et al., 2005). Although the importance of comprehending intraspecific physiological variation has been appreciated for some time (Spicer \& Gaston, 1999), relatively few studies of this kind have been undertaken for arthropod vectors of human and animal disease (but see Rajagopal \& Bursell, 1966;

\footnotetext{
Correspondence: John S. Terblanche, Centre for Invasion Biology, Stellenbosch University, Private Bag X1, Matieland, 7602, South Africa. Tel.: +27 21808 2605; fax: +27 21808 2405; e-mail: jst@ sun.ac.za
}

Taylor, 1977; Lighton et al., 1993; Fielden et al., 1999; Terblanche et al., 2004, 2005; Gray \& Bradley, 2005).

Owing to their status as vectors of trypanosomes, there is much interest in understanding the factors influencing distribution and abundance of tsetse (Rogers \& Robinson, 2004). Metabolic rates are important in this regard because they can be used to determine energy budgets (Bursell \& Taylor, 1980), which provide insight into flight durations, and hence daily dispersal rates. In turn, dispersal rates can provide insight into population structure, potential gene flow both within and among populations, and the mechanisms that might limit the geographical ranges of species (Krafsur et al., 2001; Lenormand, 2002; Gaston, 2003). Furthermore, there is a strong positive relationship between temperature and population mortality rates in tsetse (Hargrove, 2004). Thus, because of its influence on energy budgets, the temperature-dependence of metabolic rate may provide insight into why mortality rates change as temperature varies at daily to seasonal scales. Metabolic rate-temperature relationships can also act as a proxy for changes in feeding requirements across spatially and temporally varying environments, and can thus serve as a potential surrogate for disease transmission rates 
(biting frequency) (for rationale, see Bursell \& Taylor, 1980). Ultimately, comprehending the sources of variation in fly mortality and disease transmission rates is essential for modelling and predicting the likely effects of future climate change on the transmission of trypanosomiasis (Rogers \& Packer, 1993; Githeko et al., 2000; Patz et al., 2000).

Although metabolic rate and its variation have been investigated previously in adults of the tsetse taxa Glossina morsitans morsitans, Glossina pallidipes and Glossina morsitans centralis (Machado) pupae (Terblanche et al., 2005), no such information is currently available for G. m. centralis adults and, indeed, the majority of tsetse taxa. In the present study, the influence that temperature, body mass, gender and feeding status have on metabolic rate in $G$. m. centralis adults is examined. Moreover, the information is combined with that obtained in previous studies and preliminary comparisons among three species are presented.

\section{Materials and methods}

\section{Study animals and laboratory conditions}

Pupae of G. m. centralis (Diptera, Glossinidae) were obtained from the laboratory colony maintained at the Entomology Unit, FAO/IAEA Agriculture and Biotechnology Laboratory, Seibersdorf, International Atomic Energy Agency, Vienna, Austria. Gene diversities in closely related G. pallidipes and G. m. morsitans suggest that laboratory flies are usually within the range of field populations (Krafsur \& Wohlford, 1999; Wohlford et al., 1999). For a different laboratory colony (from Singida, Tanzania) to the one used in the present study, gene diversity appeared to be relatively well-conserved among laboratory and field populations in G. m. centralis (Krafsur et al., 2001).

On receipt, pupae were immediately placed inside plastic containers and transferred to a climate chamber set to $24{ }^{\circ} \mathrm{C}$ $\left(24.6 \pm 2.5^{\circ} \mathrm{C}\right.$, under an LD $12: 12 \mathrm{~h}$ photoperiod). Relative humidity was regulated to $76 \%$ by means of saturated salt $(\mathrm{NaCl})$ solutions located within each container. Flies were transferred to mesh cages ( $10 \mathrm{~cm}$ in diameter, $n=25-35$ per cage) after eclosion for use in various gender and feeding categories. All cages were located within closed, non-airtight plastic containers that also held $150-\mathrm{mL}$ jars containing the saturated salt solution. Feeding took place using a membrane-tray system (Gooding et al., 1997) on alternate days using defibrinated bovine blood (similar to methods described previously in Terblanche et al., 2004, 2005), at which point container locations were randomized within climate chambers to preclude shelf effects.

Tsetse are exclusively haematophagous, relatively longlived flies ( $>3$ months as adults in the wild), which reproduce by adenotrophic viviparity (tsetse ecology and biology is reviewed in Leak, 1999). Male and female flies were used in fed and fasted states for respirometry recordings. Flies used for respirometry approximately $1 \mathrm{~h}$ after a bloodmeal were considered 'fed', whereas flies that had not fed for at least $36 \mathrm{~h}$ were considered 'fasted'. Unmated females, separated from males at eclosion, were used in the female category. All flies used in these experimental classes were reared in climate chambers set at $24-25{ }^{\circ} \mathrm{C}$ with the same photoperiod and humidity described for pupal rearing conditions (see above). The duration between feeding and respirometry recording, as well as the duration between temperature treatments, was standardized across all experimental groups to maintain consistency between species. Flies used for respirometry experiments had received between six and 11 bloodmeals, and were therefore aged 12-22 days old. Thus, they were also at an age when posteclosion flight muscle developmental effects on metabolic rate are at a minimum (Terblanche et al., 2004). All experimental and rearing facilities were housed in airconditioned, quarantine-approved laboratories.

\section{Metabolic rates}

Metabolic rates were recorded as carbon dioxide production using flow-through respirometry similar to methods described previously (Terblanche et al., 2005). In brief, a LI-6262 (LiCor, Lincoln, Nebraska) infra-red gas analyser was connected to a Sable Systems International (Las Vegas, Nevada) eight channel multiplexer housed inside a Sable Systems PTC-1 temperature-controlled cabinet (accuracy of $\pm 0.1^{\circ} \mathrm{C}$ ). Compressed air, scrubbed of $\mathrm{CO}_{2}$ (using soda lime) and water (using silica gel and drierite) was pushed through the multiplexer and the 5-mL cuvettes housing the flies and regulated to $100 \mathrm{~mL} \mathrm{~min}^{-1}$ using a mass flow controller (Sierra Instruments, Monterey, CA). The first seven channels of the multiplexer regulated the flow-through respirometry for individual flies and channel eight was used as an empty reference channel for $\mathrm{CO}_{2}$ and $\mathrm{H}_{2} \mathrm{O}$ baseline measurements. The multiplexer regulated airflow through channels 1-7 consecutively for $14 \mathrm{~min}$ at a time during one recording (sampling rate $=1 \mathrm{~s}$ ). When the active channel was being recorded, an additional airflow line was set up to flush the other six inactive channels to prevent the build-up of $\mathrm{CO}_{2}$ and water vapour in the cuvettes. A thermocouple, connected to a Sable Systems TC1000 Thermocouple meter, was inserted into the first cuvette to measure the temperature inside a respirometry chamber containing an individual fly. The PTC-1 temperature was manually set at $20,24,28$ and $32{ }^{\circ} \mathrm{C}$ at the start of each test temperature's respirometry recording. The test temperatures were fixed in increasing order during all experiments. Respirometry recording was only started once the cuvette temperature was within $0.5^{\circ} \mathrm{C}$ of the target test temperature. A Sable Systems AD-1 electronic activity detector was connected to the first cuvette only and used to identify $\mathrm{CO}_{2}$ traces representative of stable, resting metabolic rate. Active metabolic rates are easily detected on individuals for which the AD-1 was not attached because there is a several-fold increase in metabolic rate for a given mass within an individual. Similar resting traces to those obtained on channel 1 were then selected for all other flies for analysis of standard metabolic rate at a given temperature. All electronic units were connected to a desktop computer and Sable Systems DATACAN V software was used for instrument control and 
data acquisition, and to extract and analyse resting (inactive) metabolic rate data. These recordings were performed for males $(n=7)$ and females $(n=7)$ separately at each of the temperatures among the various experimental categories. This process was repeated twice for each of the experimental groups investigated $(n=14$ for each gender $\times$ feeding status category). Flies were selected at random from all available cages for use in an experimental category to minimize any cage by treatment effect. Mass was recorded before and after respirometry recordings using a calibrated electronic balance (0.1 mg; FA 304T, Avery Berkel, Fairmont, Minnesota).

\section{Statistical analyses}

Metabolic rate and body mass data were checked for normality using a Shapiro-Wilks test, and where necessary distributions were normalized by $\log _{10}$ transformation (Zar, 1999). The effects of feeding status, gender, test temperature, mass and interactions of the categorical variables on $\log _{10}$ metabolic rate were assessed using general linear models. The mean body mass (as determined from weighing before and after respirometry runs) of each individual was included as a covariate to ensure that its strong effect on metabolic rate was accounted for. Ordinary least-squares regressions were used to describe metabolic rate-temperature and metabolic rate-body mass relationships for G. m. centralis, for comparison with previous data obtained using the same methods, for G. m. morsitans and G. pallidipes (Terblanche et al., 2004, 2005). All analyses were performed using Statistica, version 7.0 (Statsoft Inc., Tulsa, Oklahoma). Data are presented as means $\pm \mathrm{SE}$ of the mean unless otherwise stated. $P=0.05$ was considered statistically significant.

\section{Results and Discussion}

Inactive (standard) metabolic rates determined for G. $m$. centralis in various feeding and gender categories at four temperatures $\left(20,24,28\right.$ and $\left.32{ }^{\circ} \mathrm{C}\right)$ showed that both temperature and body mass have a significant positive effect on metabolic rate (Tables 1 and 2). Gender did not significantly affect metabolic rate after controlling for body mass, although feeding status and gender by feeding status effects were both significant (Table 2). The interaction effect occurred because female flies had a higher metabolic rate when fed than when fasted, but in males this was more variable. Similarly, within each experimental category, temperature and body mass always had strong positive effects (Table 3 ).

The present study adds confidence to previously reported metabolic rate data for adult tsetse (Rajagopal \& Bursell, 1966; Taylor, 1977, 1978; Hargrove \& Coates, 1990; Terblanche et al., 2004, 2005). For example, it is well established in G. pallidipes and G. m. morsitans that metabolic rate does not differ between males and females once the effects of body size are taken into account (Rajagopal \& Bursell, 1966; Taylor, 1977; Terblanche et al., 2004), and that females have a higher metabolic rate when mass effects
Table 1. Summary statistics for the gender and feeding categories used in the determination of (resting) standard metabolic rates $\left(\mathrm{VCO}_{2}\right)$ in Glossina morsitans centralis.

\begin{tabular}{|c|c|c|c|c|}
\hline Gender & $\begin{array}{l}\text { Temperature } \\
\left({ }^{\circ} \mathrm{C}\right)\end{array}$ & $\begin{array}{l}\text { Feeding } \\
\text { state }\end{array}$ & Mass (mg) & $\mathrm{VCO}_{2}\left(\mu \mathrm{L} \mathrm{h}^{-1}\right)$ \\
\hline \multirow[t]{8}{*}{ Male } & \multirow[t]{2}{*}{20} & Fed & $29.58 \pm 1.66$ & $13.93 \pm 0.86$ \\
\hline & & Fasted & $22.72 \pm 1.41$ & $17.76 \pm 2.23$ \\
\hline & \multirow[t]{2}{*}{24} & Fed & & $19.46 \pm 0.86$ \\
\hline & & Fasted & & $19.78 \pm 3.11$ \\
\hline & \multirow[t]{2}{*}{28} & Fed & & $28.75 \pm 1.60$ \\
\hline & & Fasted & & $27.43 \pm 3.79$ \\
\hline & \multirow[t]{2}{*}{32} & Fed & & $40.94 \pm 1.74$ \\
\hline & & Fasted & & $33.22 \pm 3.90$ \\
\hline \multirow[t]{8}{*}{ Female } & \multirow[t]{2}{*}{20} & Fed & $37.53 \pm 2.29$ & $21.51 \pm 2.02$ \\
\hline & & Fasted & $29.28 \pm 1.96$ & $17.58 \pm 2.40$ \\
\hline & \multirow[t]{2}{*}{24} & Fed & & $30.68 \pm 3.97$ \\
\hline & & Fasted & & $27.34 \pm 3.86$ \\
\hline & \multirow[t]{2}{*}{28} & Fed & & $43.15 \pm 4.35$ \\
\hline & & Fasted & & $35.51 \pm 4.94$ \\
\hline & \multirow[t]{2}{*}{32} & Fed & & $56.35 \pm 4.51$ \\
\hline & & Fasted & & $43.18 \pm 4.66$ \\
\hline
\end{tabular}

Data are presented as means \pm SE. Data were sampled at $1 \mathrm{~Hz}$ using flow-through respirometry in a darkened temperature-controlled chamber ( $n=14$ in all cases).

are not removed. This is the case for G. m. centralis too. Consequently, the direct effects of feeding and sex-related body size variation on metabolic rate are well documented for three tsetse taxa, namely G. m. morsitans, G. pallidipes and now also for G. m. centralis. Moreover, the interaction between feeding status and gender on metabolic rate, previously documented in G. m. morsitans (Terblanche et al., 2005), is now also been confirmed for G. m. centralis. Thus, it appears that, at least in Morsitans group tsetse flies, females show a typical effect of feeding on metabolic rate (Chown \& Nicolson, 2004) whereas, in males, this effect is realized only at high temperatures, if at all. Physiologically, it is unlikely that males would show no specific dynamic action. Therefore, the difference between the sexes might be a consequence of different time-courses of specific dynamic

Table 2. Results of a general linear model analysis of standard (resting) metabolic rates $\left(\log _{10} \mathrm{~mL} \mathrm{CO}_{2} \cdot \mathrm{h}^{-1}\right)$ in Glossina morsitans centralis.

\begin{tabular}{lrlrr}
\hline Effect & d.f. & \multicolumn{1}{l}{ MS } & \multicolumn{1}{l}{$F$} & $P$ \\
\hline Intercept & 1 & 0.3034 & 20.270 & $<0.001$ \\
Temperature & 1 & 5.0416 & 336.890 & $<0.001$ \\
Log $_{10}$ mass & 1 & 3.0726 & 205.314 & $<0.001$ \\
Gender & 1 & 0.0039 & 0.257 & 0.612 \\
Feeding status & 1 & 0.2005 & 13.397 & $<0.001$ \\
Gender $\times$ feeding status & 1 & 0.0822 & 5.491 & $<0.05$ \\
Error & 218 & 0.0150 & & \\
\hline
\end{tabular}

Temperature and body mass were treated as continuous variables, whereas gender and feeding status were considered fixed effects. d.f., degrees of freedom; MS, mean squares. 
Table 3. Summary of multiple regression relationships of $\log _{10}$ metabolic rate $\left(\mathrm{mL} \mathrm{CO}_{2} \mathrm{~h}^{-1}\right)$ (dependent variable) against temperature $\left({ }^{\circ} \mathrm{C}\right)$ and $\log _{10}$ body mass (g) (independent variables) within the experimental classes investigated for Glossina morsitans centralis.

\begin{tabular}{|c|c|c|c|c|c|c|}
\hline Category & Variable & Slope \pm SE & $r^{2}$ & $t$-value & d.f. & $P$ \\
\hline Males & Intercept & $-2.290 \pm 0.194$ & & -11.827 & 53 & $<0.001$ \\
\hline \multirow[t]{3}{*}{ Fed } & Temperature & $0.040 \pm 0.003$ & & 16.076 & 53 & $<0.001$ \\
\hline & $\log _{10}$ mass & $0.244 \pm 0.119$ & & 2.057 & 53 & $<0.05$ \\
\hline & & & 0.832 & $131.34 *$ & 2,53 & $<0.001$ \\
\hline Males & Intercept & $0.342 \pm 0.241$ & & 1.422 & 53 & 0.161 \\
\hline \multirow{3}{*}{ Fasted } & Temperature & $0.025 \pm 0.003$ & & 8.853 & 53 & $<0.001$ \\
\hline & $\log _{10}$ mass & $1.600 \pm 0.139$ & & 11.541 & 53 & $<0.001$ \\
\hline & & & 0.800 & $105.79 *$ & 2,53 & $<0.001$ \\
\hline Females & Intercept & $-0.347 \pm 0.239$ & & -1.452 & 53 & 0.153 \\
\hline \multirow[t]{3}{*}{ Fed } & Temperature & $0.036 \pm 0.003$ & & 10.979 & 53 & $<0.001$ \\
\hline & $\log _{10}$ mass & $1.444 \pm 0.155$ & & 9.309 & 53 & $<0.001$ \\
\hline & & & 0.796 & $103.60 *$ & 2,53 & $<0.001$ \\
\hline Females & Intercept & $-0.279 \pm 0.285$ & & -0.979 & 53 & 0.332 \\
\hline \multirow[t]{3}{*}{ Fasted } & Temperature & $0.034 \pm 0.004$ & & 7.890 & 53 & $<0.001$ \\
\hline & $\log _{10}$ mass & $1.408 \pm 0.169$ & & 8.324 & 53 & $<0.001$ \\
\hline & & & 0.713 & $65.776^{*}$ & 2,53 & $<0.001$ \\
\hline
\end{tabular}

$* F$-value.

action (Terblanche et al., 2005). Only frequently logged, continuously recorded data from resting individuals, which are then fed, can be used to correctly observe the postprandial peak in respiration rate (Bradley et al., 2003). Clearly, such

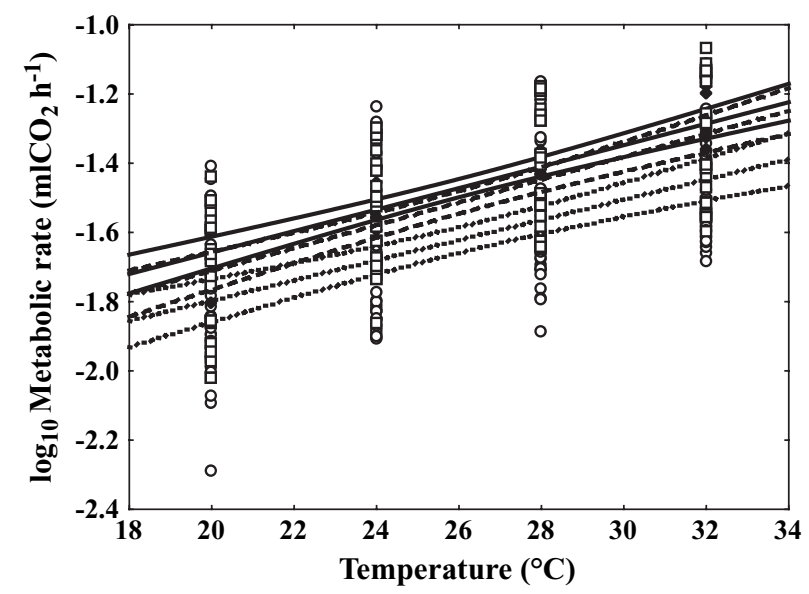

Fig. 1. The relationship between temperature (in ${ }^{\circ} \mathrm{C}$ ) and $\log _{10}$ standard (resting) metabolic rate (in $\mathrm{mL} \mathrm{CO}_{2} \mathrm{~h}^{-1}$ ) in three tsetse species. Glossina pallidipes $(n=27)$ : slope $=0.0310 \pm 0.00304$; intercept $=-2.278 \pm 0.077 ;$ Glossina morsitans morsitans $(n=111)$ : slope $=0.0329 \pm 0.00371$; intercept $=-2.370 \pm 0.097$; Glossina morsitans centralis $(n=112)$ : slope $=0.0292 \pm 0.00419$; intercept $=-$ $2.380 \pm 0.111(P<0.001$ in all cases; values from unfed males and females, except in G. pallidipes, which is for unfed males only). Circles (dotted lines), G. m. centralis; squares (dashed lines), G. m. morsitans; diamonds (solid lines), G. pallidipes. All values were obtained using flow-through respirometry under similar experimental and rearing conditions. work is required in tsetse before specific dynamic action and its variation with temperature can be fully understood.

The effects of body mass and temperature on metabolic rate have now been documented explicitly for G. pallidipes,

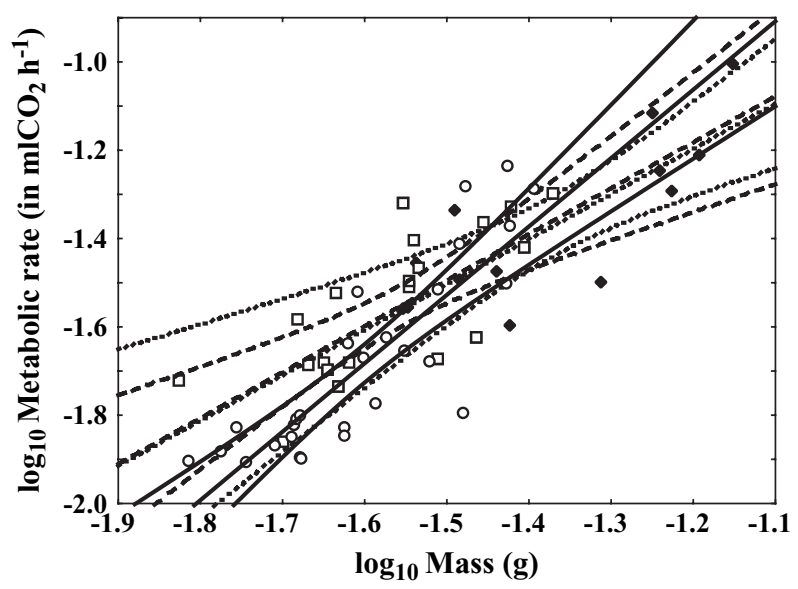

Fig. 2. The relationship between $\log _{10}$ body mass $(\mathrm{g})$ and $\log _{10}$ standard (resting) metabolic rate $\left(\mathrm{mL} \mathrm{CO}_{2} \mathrm{~h}^{-1}\right)$ in three tsetse species (Diptera, Glossinidae) derived from ordinary least-squares regression. Lines represent means ( $\pm 95 \%$ confidence limits) for each species. Glossina pallidipes $(n=13)$ : slope $=1.026 \pm 0.220$; intercept $=0.034 \pm 0.303 ;$ Glossina morsitans morsitans $(n=27)$ : slope $=$ $1.041 \pm 0.209 ;$ intercept $=0.067 \pm 0.325 ;$ Glossina morsitans centralis $(n=28)$ : slope $=1.549 \pm 0.184$; intercept $=0.796 \pm 0.295$ $(P<0.001$ in all cases; values from unfed males and females). Circles (dotted lines), G. m. centralis; squares (dashed lines), G. m. morsitans; diamonds (solid lines), G. pallidipes. All values were obtained using flow-through respirometry under similar experimental and rearing conditions. 
G. m. morsitans and G. m. centralis (Figs 1 and 2). The slopes and intercepts of the metabolic rate-body mass relationships do not differ among the three taxa [analysis of covariance (ANCOVA): slopes: $F_{2,62}=2.27 ; P=0.11$; intercept: $F_{2,62}=$ $1.97 ; P=0.15$ ] (Fig. 2). Moreover, there is no significant difference in the slopes (ANCOVA: $F_{2,244}=0.25 ; P=0.77$ ) or intercepts $\left(F_{2,244}=0.10 ; P=0.90\right)$ of the metabolic ratetemperature relationships (Fig. 1). The similar responses to temperature are akin to the small differences in temperature preference among the species shown in the modelling work (Rogers \& Robinson, 2004). In practice, these data can have applications in both modelling disease transmission rates and population dynamics. For example, in the former case, assuming disease transmission rates increase proportionally with biting frequency, potential transmission rates might increase by $116-146 \%$ across a $5{ }^{\circ} \mathrm{C}$ range, or by $165-213 \%$ across a $10{ }^{\circ} \mathrm{C}$ range, as a result of greater metabolic requirements. Increases in feeding frequency resulting from warmer temperatures may occur at a cost because this may increase risktaking events (Yearsley et al., 2005), thereby causing an increase in mortality. Over longer timescales, an increase in mortality rates may ultimately offset the potential increases in disease transmission rates caused by higher temperatures. Determining the trade-offs between increased feeding requirements and disease transmission, and their potential impact on population dynamics at warmer temperatures, will require further experimental work, but it is of considerable importance for predicting the effects of anthropogenic climate change on trypanosomiases distribution and abundance (Rogers \& Packer, 1993; Githeko et al., 2000; Patz et al., 2000).

In conclusion, these data show that the responses of metabolic rate to temperature, mass, gender and feeding are consistent among at least three tsetse taxa. Furthermore, the potential for bottom-up modelling of population dynamics using physiologically-derived parameters for metabolic rate and its dependence on temperature and body mass now exists for some tsetse. Future work in the area might usefully extend these results to other tsetse species to determine whether the results are applicable to other tsetse groups, and include the pupal stages, for which the effects of temperature on metabolic rate are known only for G. m. centralis (Rajagopal \& Bursell, 1965).

\section{Acknowledgements}

We thank Jaco Klok and Erika Nortje for technical assistance. This work was funded by an NIH grant AI-52456 to E. S. Krafsur. Emilie Gray and Elrike Marais provided useful comments on an earlier version of this manuscript.

\section{References}

Bradley, T.J., Brethorst, L., Robinson, S. \& Hetz, S. (2003) Changes in the rate of $\mathrm{CO}_{2}$ release following feeding in the insect Rhodnius prolixus. Physiological and Biochemical Zoology, 76, 302-309.
Bursell, E. \& Taylor, P. (1980) An energy budget for Glossina (Diptera: Glossinidae). Bulletin of Entomological Research, 70, 187-196.

Chown, S.L. \& Nicolson, S.W. (2004) Insect Physiological Ecology Mechanisms and Patterns. Oxford University Press, U.K.

Fielden, L.J., Jones, R.M., Goldberg, M. \& Rechav, Y. (1999) Feeding and respiratory gas exchange in the American dog tick, Dermacentor variabilis. Journal of Insect Physiology, 45, 297-304.

Gaston, K.J. (2003) The Structure and Dynamics of Geographyraphic Ranges. Oxford University Press, U.K.

Githeko, A.K., Lindsay, S.W., Confalonieri, U.E. \& Patz, J.A. (2000) Climate change and vector-borne diseases: a regional analysis. Bulletin of the World Health Organisation, 78, 1136-1147.

Gooding, R.H., Feldmann, U. \& Robinson, A.S. (1997) Care and maintenance of tsetse colonies. The Molecular Biology of Insect Disease Vectors (ed. by J.M. Crampton, C.B. Beard and C. Louis), pp. 41-55. Chapman \& Hall, U.K.

Gray, E.M. \& Bradley, T.J. (2005) Malarial infection in Aedes aegypti: effects on feeding, fecundity and metabolic rate. Parasitology, 132, 1-8.

Hargrove, J.W. (2004) Tsetse population dynamics. The Trypanosomiases (ed. by I. Maudlin, P. H. Holmes and M. A. Miles), pp. 113-138. CABI Publishing, U.K.

Hargrove, J.W. \& Coates, T.W. (1990) Metabolic rates of tsetse flies in the field as measured by the excretion of injected cesium. Physiological Entomology, 15, 157-166.

Krafsur, E.S., Endsley, M.A., Wohlford, D.L. et al. (2001) Genetic differentiation of Glossina morsitans centralis populations. Insect Molecular Biology, 10, 387-395.

Krafsur, E.S. \& Wohlford, D.L. (1999) Breeding structure of Glossina pallidipes populations evaluated by mitochondrial variation. Journal of Heredity, 90, 635-642.

Leak, S.G.A. (1999) Tsetse Biology and Ecology Their Role in the Epidemiology and Control of Trypanosomosis. CABI Publishing, New York, New York.

Lenormand, T. (2002) Gene flow and the limits to natural selection. Trends in Ecology and Evolution, 17, 183-189.

Lighton, J.R.B., Fielden, L.J. \& Rechav, Y. (1993) Discontinuous ventilation in a non-insect, the tick Amblyomma marmoreum (Acari, Ixodidae): characterization and metabolic modulation. Journal of Experimental Biology, 180, 229-245.

Patz, J.A., Graczyk, T.K., Geller, N. \& Vittor, A.Y. (2000) Effects of environmental change on emerging parasitic diseases. International Journal for Parasitology, 30, 1395-1405.

Rajagopal, P.K. \& Bursell, E. (1965) The effect of temperature on the oxygen consumption of tsetse pupae. Bulletin of Entomological Research, 56, 219-225.

Rajagopal, P.K. \& Bursell, E. (1966) The respiratory metabolism of resting tsetse flies. Journal of Insect Physiology, 12, 287-297.

Rogers, D.J. \& Packer, M.J. (1993) Vector-borne diseases, models, and global change. Lancet, 342, 1282-1284.

Rogers, D.J. \& Robinson, T.P. (2004) Tsetse distribution. The Trypanosomiases (ed. by I. Maudlin, P. H. Holmes and M. A. Miles), pp. 139-180. CABI Publishing, U.K.

Spicer, J.I. \& Gaston, K.J. (1999) Physiological Diversity and its Ecological Implications. Blackwell Science, U.K.

Taylor, P. (1977) The respiratory metabolism of the tsetse (Diptera: Glossinidae) in relation to temperature, blood-meal size and the pregnancy cycle. Physiological Entomology, 2, 317-322.

Taylor, P. (1978) Radioisotopes as metabolic labels for Glossina (Diptera: Glossinidae). I. Laboratory determination of the relationship between radioisotope metabolism, respiration and temperature. Bulletin of Entomological Research, 68, 1-9.

Terblanche, J.S., Klok, C.J. \& Chown, S.L. (2004) Metabolic rate variation in Glossina pallidipes (Diptera: Glossinidae): gender, 
ageing and repeatability. Journal of Insect Physiology, 50, 419-428.

Terblanche, J.S., Klok, C.J. \& Chown, S.L. (2005) Temperaturedependence of metabolic rate in Glossina morsitans morsitans (Diptera, Glossinidae) does not vary with gender, age, feeding, pregnancy or acclimation. Journal of Insect Physiology, 51, $861-870$

Wohlford, D.L., Krafsur, E.S., Griffiths, N.T. et al. (1999) Genetic differentiation of some Glossina morsitans morsitans populations. Medical and Veterinary Entomology, 13, 377-385.
Yearsley, J.M., Kyriazakis, A., Gordon, I.J. et al. (2005) A life history model of somatic damage associated with resource acquisition: damage protection or prevention? Journal of Theoretical Biology, 235, 305-317.

Zar, J.H. (1999) Biostatistical Analysis. Prentice Hall, Inc., Princeton, New Jersey.

Accepted 24 August 2006

First published online 25 January 2007 